\title{
Numerical Simulation of Characteristics of Cavitation and Aeration in Free-flow Tunnel
}

\author{
Yang XUE ${ }^{1, a}$, Zhi-Ping LIU ${ }^{2}$, Jian-Rong XU ${ }^{1}$, Yu PENG ${ }^{1}$ \\ ${ }^{1}$ Powerchina Huadong Engineering Corporation Limited, Hangzhou, China \\ ${ }^{2}$ Institute of water resources and hydropower research, Beijing, China \\ axue_y3@ecidi.com
}

Keywords: Free-flow Tunnel, Cavitation, Aeration, Realizable k- $\varepsilon$ Model, Volume of Fluid.

\begin{abstract}
Outlet structures were apt to occur cavitation damages with high speed flow, and aerators were usually adopted to reduce and eliminate cavitation damages in hydropower project. In this paper, the Realizable k- $\varepsilon$ model and the Volume of Fluid method were used to simulate the characteristics of cavitation and aeration of the free-flow tunnel in Baihetan Hydropower Station. The distributions of water surface profile, pressure, flow velocity and cavitation number were gained. The results show that the Realizable k- $\varepsilon$ model and VOF method were good at simulating the aerated flow of the free-flow tunnel. Aerators position is the main reason for the changes of velocity distribution in a cross section. The design parameters of the free-flow tunnel in Baihetan Hydropower Station are reasonable by the stable aerated cavities and the suitable length.
\end{abstract}

\section{Introduction}

The free-flow tunnel with high velocity and high water-head is prone to cavitation and lead to cavitation damage on flowing surface. It is a simple, economic and effective engineering measure for eliminating cavitation damages on flowing surface to set aerator devices on the place where is easy to cavitation. In recent years, besides conventional physical model test[1 3], with the development of turbulent numerical simulation technology, the simulation of turbulent flow gradually become an indispensable research way to investigate the characteristics of aerated flow of high water-head tunnel. Standard k- $\varepsilon$ model and RNG k- $\varepsilon$ model were induced in most of numerical simulation before[4 9], Standard k- $\varepsilon$ model is the most simple double equation model in turbulence numerical simulation, it would produce a certain distortion when was used to simulate flow motion in curved streamlines. Then, the RNG k- $\varepsilon$ model was put forward to solve high strain rate and large streamline curvature motion equation, but the singularity of $\varepsilon$ equation should be discussed[10]. In the Realizable k- $\varepsilon$ model, the coefficients $C_{\mu}$ in the $\varepsilon$ equation was no longer regarded as a constant, but was linked with strain rate and turbulent parameters and set a new $\varepsilon$ equation to avoid singularity problem.

In this paper, the combination of the Realizable k- $\varepsilon$ model and VOF method was applied to simulate characteristics of aerated flow of the free-flow tunnel in Baihetan Hydropower Station. The results of numerical simulation were comparied with experimental data, and the analysis provided the basis for the further research work of aeration of free-flow tunnel.

\section{Calculation Model}

The Realizable k- $\varepsilon$ model was applied to solve the two phase flow and the basic control equations were described as follows:

$$
\begin{aligned}
& \text { Equation of continuity: } \frac{\partial \rho}{\partial t}+\frac{\partial}{\partial x_{i}}\left(\rho u_{i}\right)=0 \\
& \text { Equation of momentum: } \frac{\partial}{\partial t}\left(\rho u_{i}\right)+\frac{\partial}{\partial x_{j}}\left(\rho u_{i} u_{j}\right)=-\frac{\partial p}{\partial x_{i}}+\frac{\partial}{\partial x_{j}}\left\lfloor\mu \frac{\partial u_{i}}{\partial x_{j}}+\mu_{t}\left(\frac{\partial u_{i}}{\partial x_{j}}+\frac{\partial u_{j}}{\partial x_{i}}\right)\right\rfloor-g_{i}
\end{aligned}
$$


k Equation: $\frac{\partial(\rho k)}{\partial t}+\frac{\partial\left(\rho k u_{i}\right)}{\partial x_{i}}=\frac{\partial}{\partial x_{j}}\left\lfloor\left(\mu+\frac{\mu_{t}}{\sigma_{k}}\right) \frac{\partial k}{\partial x_{j}}\right\rfloor+G_{k}-\rho \varepsilon$

$\varepsilon$ Equation: $\left.\frac{\partial(\rho \varepsilon)}{\partial t}+\frac{\partial\left(\rho \varepsilon u_{i}\right)}{\partial x_{i}}=\frac{\partial}{\partial x_{j}} \mid\left(\mu+\frac{\mu_{t}}{\sigma_{\varepsilon}}\right) \frac{\partial \varepsilon}{\partial x_{j}}\right\rfloor+\rho C_{1} E \varepsilon-\rho C_{2} \frac{\varepsilon^{2}}{k+\sqrt{v \varepsilon}}$

where, $\mathrm{u}$ is velocity vector; $\mathrm{P}$ is pressure; $\rho$ is density; $\mu$ is viscosity; $\mathrm{g}$ is acceleration of gravity; constant coefficient $\sigma_{k}=1.0, \sigma_{\varepsilon}=1.2, C_{2}=1.9$; coefficient

$$
C_{1}=\max \left(0.43, \frac{\eta}{\eta+5}\right), \eta=\left(2 E_{i j} \bullet E_{i j}\right)^{0.5} \frac{k}{\varepsilon}, E_{i j}=\frac{1}{2}\left(\frac{\partial u_{i}}{\partial x_{j}}+\frac{\partial u_{j}}{\partial x_{i}}\right), G_{k}=\mu_{t}\left(\frac{\partial u_{i}}{\partial x_{j}}+\frac{\partial u_{j}}{\partial x_{i}}\right) \frac{\partial u_{i}}{\partial x_{j}} ;
$$

where $\mu_{t}$ is turbulent viscosity, it is calculated by turbulent kinetic energy and turbulent dissipation rate:

$$
\mu_{t}=\rho C_{\mu} \frac{k^{2}}{\varepsilon}
$$

In the equation, $C_{\mu}$ is no longer a constant, it is described as follows:

$$
C_{\mu}=\frac{1}{A_{0}+A_{s} U^{*} k / \varepsilon}
$$

Where, $A_{0}=4.0, A_{s}=\sqrt{6} \cos \left\{\frac{1}{3} \cos ^{-1}\left\lfloor\sqrt{6}\left(\frac{E_{i j} E_{j k} E_{k i}}{\sqrt{E_{i j} E_{i j}}}\right)\right\rfloor\right\}, U^{*}=\sqrt{E_{i j} E_{i j}+\left(\Omega_{i j}-2 \varepsilon_{i j} \omega_{k}\right)\left(\Omega_{i j}-2 \varepsilon_{i j} \omega_{k}\right)}$.

The time averaged rotation rate tensor $\Omega_{i j}=\frac{1}{2}\left(\frac{\partial u_{i}}{\partial x_{j}}+\frac{\partial u_{j}}{\partial x_{i}}\right)$.

The VOF method was applied to track the interface between water phase and air phase in this paper. A particular phase $\mathrm{F}$ was identified by its volume fraction in a computational cell. If $\mathrm{F}=1$, the cell is full of water; if $\mathrm{F}=0$, the cell is full of air; and if $0<\mathrm{F}<1$, the cell contains the interface between the water phase and air phase. The equation for $\mathrm{F}$ in its conservative form can be written as:

$$
\frac{\partial f}{\partial t}+v \cdot \nabla f=0
$$

There were a lot of different method to construct interface in VOF, the geometry reconstruction interface was obtained in this paper, for the method can accurately track the interface.

\section{Computational Domains and Mesh Generation}

The tunnel of Baihetan Hydropower Station was comprised of flat slope, ogee curve, steep slope and anti-arc. Because of the high velocity, three aerators were set to avoid cavitation damage on flowing surface, where located at stakes of $1788.3 \mathrm{~m}, 1898.33 \mathrm{~m}$, and $2048.33 \mathrm{~m}$. The total heights of bottom aerators with bucket-drop type were respectively $2.32 \mathrm{~m}, 1.9 \mathrm{~m}$ and $1.9 \mathrm{~m}$. The side wall in both sides of bottom aerator formed lateral aerator with a sudden expansion of $0.35 \mathrm{~m}$.

Although the study focused on the hydraulic characteristics of aerated flow in the tail section of tunnel, in order to avoid the impact of inlet boundary on the accuracy of calculation results, the whole tunnel section was established in calculation. The length of 10 times of inlet height was induced in length of the upstream reservoir. Calculation area was shown in figure 1. 
For avoiding the numerical dissipation appeared in the process of calculation, the grid division should be in the same direction with flow motion as far as possible. The whole tunnel section was about $2.4 \mathrm{~km}$ long, non-uniform structured grid was applied to balance computational efficiency and meet the calculation precision. The grid size of simple smooth flat slope segment and the ogee curve segment was $5 \mathrm{~m} \times 0.5 \mathrm{~m} \times 3 \mathrm{~m}$, and the grid size of the tail section with complicated flow condition for the aerators was $5 \mathrm{~m} \times 0.5 \mathrm{~m} \times 3 \mathrm{~m}$. The total grid cells account about 406000 . The mesh of the segments was shown in figure 2.

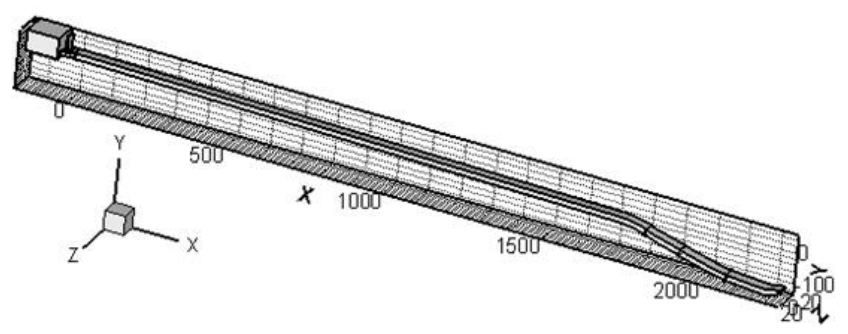

Fig. 1 Calculation Area of the Tunnel

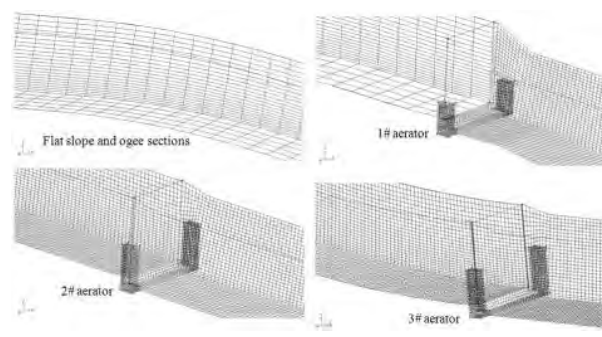

Fig. 2 Mesh Generation

\section{Boundary Condition and Calculation Method}

The water inlet was set to pressure boundary type, the static pressure distribution was applied and the upstream reservoir water level was on $832.34 \mathrm{~m}$. The outlet boundary was set to pressure-outlet type with atmosphere. The bottom and side wall were treated by standard wall function, the region above water surface was set to pressure boundary with atmosphere for the open channel flow.

The QUICK format was applied to solve equation, and the PISO algorithm was applied to solve implicit pressure and velocity coupling. The unsteady flow algorithm was induced in calculation, when calculation was stable, it stops. The discriminant condition of stable calculation was flow equilibrium of inlet and outlet is less than 5\%. The first order accuracy was applied to discrete instantaneous derivative at first, then changes to the two order accuracy till calculation was stable. In this way, we can save time and can obtain more accurate results. In this paper, the calculation time step is $0.0001 \sim 0.002 \mathrm{~s}$.

\section{Results and Analysis}

\section{Water Surface Profile and Pressure Characteristics}

The water surface profile was measures on the outer wall of organic glass in experiment, so the water surface profile on right wall was extracted to compare with experimental data, as shown in figure 3 . As can be seen from figure 3, the water surface profile near aerator has a small rise by the affection of aerator, the water surface profile decreased along the chute and remained sufficient height in the tail section of tunnel, the calculated results were in good agreement with experimental results.

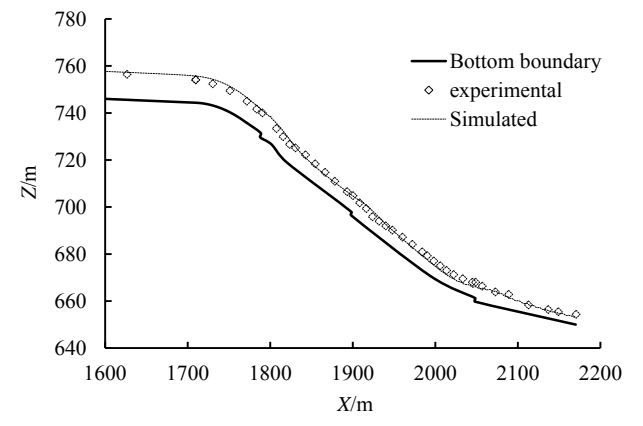

Fig. 3 The Comparision of Water Surface Profile

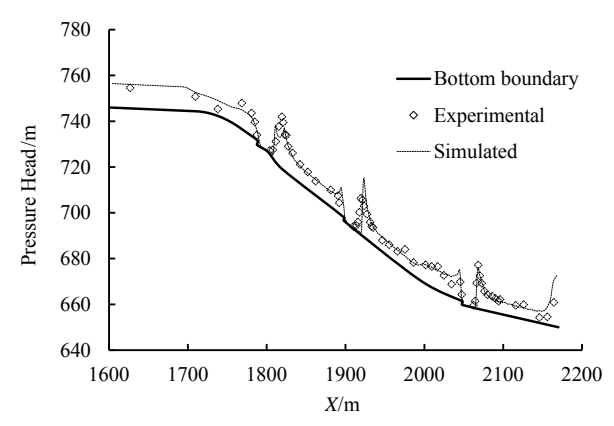

Fig. 4 The Comparision of Pressure Distribution of Bottom Boundary

The appearance of negative pressure in the high velocity zone is the main reason leading to cavitation damage of tunnel, therefore, it is required for a detailed understanding of the pressure distribution in the 
tail section of the tunnel. The time averaged pressure distribution on center line of tail section floor was shown in figure 4 . The pressure on ogee curve decreased, but still was relatively large positive pressure and wonuld not cause cavitation. The pressure distribution on bottom floor was influenced by aerator jets significantly, the pressure is suddenly increased and showed obvious peak value in jet impact zone after aerator. Calculated peak pressure on center line after three aerators were respectively $18.69 \times 9.8 \mathrm{kPa}$, $25.59 \times 9.8 \mathrm{kPa}$ and $17.97 \times 9.8 \mathrm{kPa}$. According with experimental data, the pressure distribution is reasonable except the value after $2 \#$ aerator was slightly larger than experimental value. In aerated cavity, pressure was low, which the minimum pressure was about $0.06 \times 9.8 \mathrm{kPa}$. a smaller negative pressure in the cavity can ensured the effective aeration. The pressure distribution of bottom near aerator was shown in figure 5.

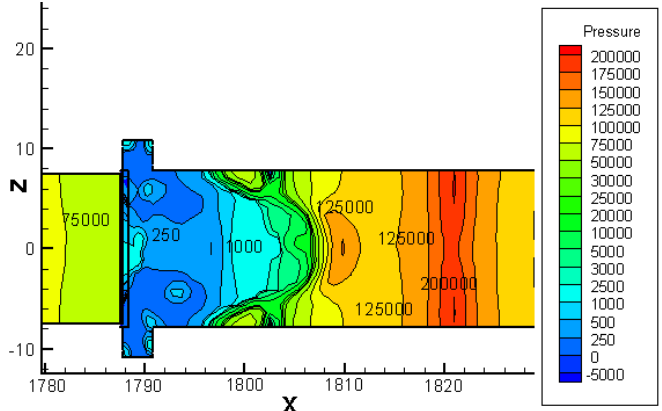

(a) 1 \# Aerator

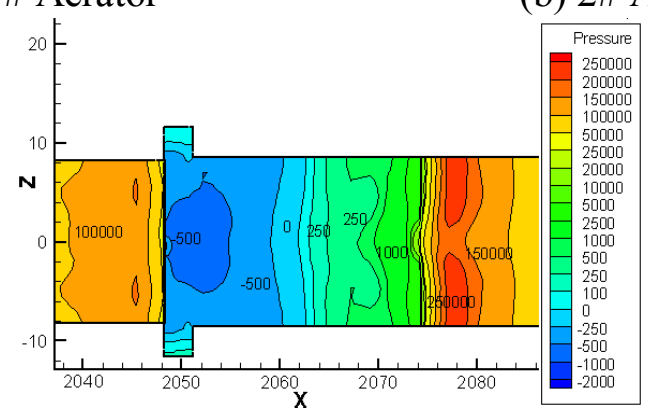

(c) 3\# Aerator

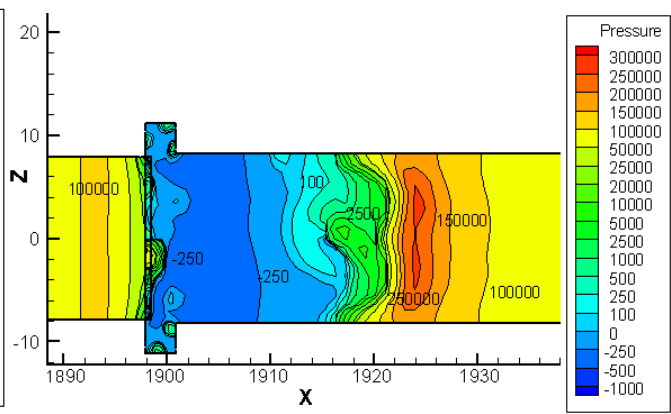

(b) $2 \#$ Aerator

Fig.5 The Bottom Pressure Distribution Near Aerators

\section{Velocity and Cavitation Number}

The velocity distribution of tail section was shown in figure 6 . The flow was smooth before $1 \#$ aerator and velocity distribution in cross section was in line with the characteristics of velocity distribution of open channel flow, which is high velocity zone appeared in the upper section. the high velocity zone gradually moved in the lower part of the section after aerator, and was symmetrically distributed on both sides, velocity isoline raised in the middle. The analysis result shows that, as the flow was aerated, velocity distribution was changed. The velocity in bubble suspended zone would increase, the air entrainment was mainly mixed by the bottom of two sides wall, air distribution was not uniform in cross section, so the high velocity zone was symmetrically distributed on both sides.

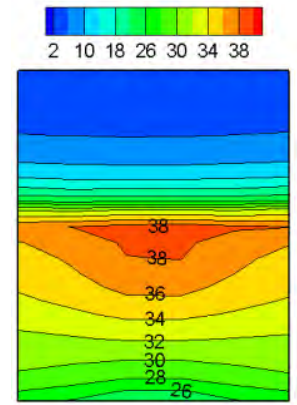

$\mathrm{X}=1788 \mathrm{~m}$

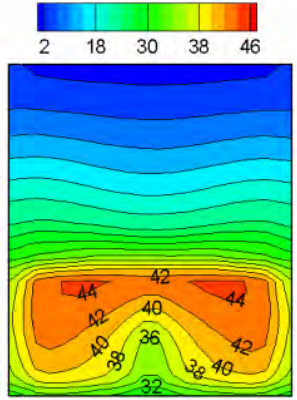

$\mathrm{X}=1898 \mathrm{~m}$

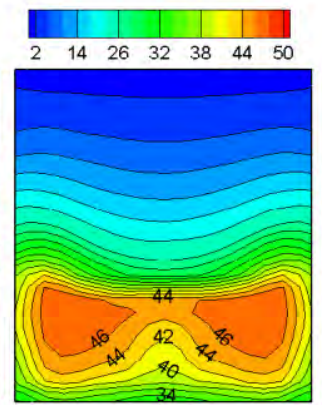

$\mathrm{X}=1994 \mathrm{~m}$

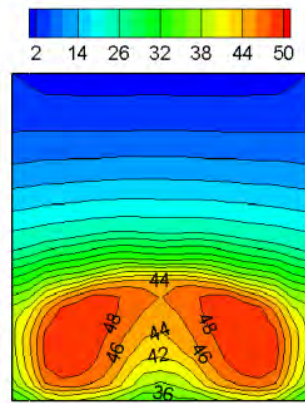

$\mathrm{X}=2048 \mathrm{~m}$

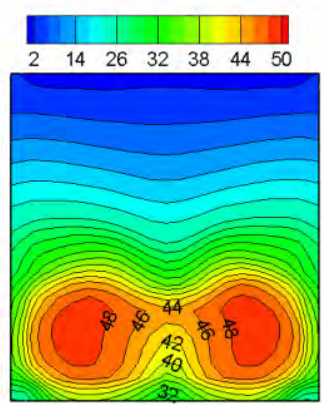

$\mathrm{X}=2170 \mathrm{~m}$

Fig.6 The Velocity Distribution of Cross Section 
The averaged velocity and flow cavitation number distribution along the feature position of tail section were listed in table 1 . It can be seen from the table that the velocity near $1 \#$ aerator was about $32 \mathrm{~m} / \mathrm{s}$ which shows the first aerator is arranged reasonably. The averaged velocity along downstream gradually increased until outlet of the tunnel, for the velocity was constrained by bucket boundary and decreased slightly. The calculation results agreed well with the model test results, which was the maximum error less than $6 \%$. The flow cavitation number was also listed in the table, and cavitation number was less than 0.3 , which showed it was necessary to set aerators.

Tab.1 The Averaged Velocity and Cavitation Number Distribution along the Feature Position

\begin{tabular}{cccccc}
\hline Position & $\begin{array}{c}\text { Stake } \\
\text { number }\end{array}$ & $\begin{array}{c}\text { Simulated } \\
\text { data }(\mathrm{m} / \mathrm{s})\end{array}$ & $\begin{array}{c}\text { Experimental } \\
\text { data }(\mathrm{m} / \mathrm{s})\end{array}$ & Error $(\%)$ & $\begin{array}{c}\text { Cavitation } \\
\text { number }\end{array}$ \\
\hline 1\# aerator & 1788 & 32.46 & 32.56 & -0.3 & 0.24 \\
2\# aerator & 1898 & 36.92 & 38.7 & -4.6 & 0.18 \\
start of anti-arc & 1994 & 39.93 & 38.9 & 2.6 & 0.18 \\
$\begin{array}{c}\text { 3\# aerator } \\
\text { (end of anti-arc) }\end{array}$ & 2048 & 41.43 & 39.15 & 5.8 & 0.18 \\
end of tunnel & 2170 & 39.21 & 38.27 & 2.5 & 0.18 \\
\hline
\end{tabular}

\section{Aeration Characteristics}

Aerated cavity with a certain length and stable shape, and no backwater are the necessary condition to ensure full aeration. The bottom aeration cavity of three aerators was shown in figure 7, the red was air and the blue was water in the figure. The flow Froude number was low near 1\# aerator, and it is hard to form a stable cavity, so the shape of variable slope bottom was applied after aerator. As can be seen from the figure, the jet tongue on slope decreased impingement angle which was in favor of eliminating the aerated cavity backwater and forming stable cavity. Also, 2\# and 3\# aerators can form stable cavity .

The comparison of cavity length between numerical calculation and model test results was shown in table 2. It can be seen from the table that the calculated cavity length of $1 \#$ aerator was smaller than the test with a difference of $-7.6 \%$; the calculated value of $2 \#$ and $3 \#$ was agree well with the test, the difference does not exceed 4\%; Overall, the calculated results agree with the model test results. According to the existing engineering research experience, the aerated cavity of established large tunnel are mostly in the range of $18 \mathrm{~m} \sim 25 \mathrm{~m}$. The cavity length was consistent with the scope of this paper. It means the parameters of aerators are reasonable and enough to meet the needs of downstream aeration. Three aerators protection length was respectively $110 \mathrm{~m}, 150 \mathrm{~m}$ and $120 \mathrm{~m}$, which was also in line with the corresponding design recommendation value.

Tab.2 The Comparison of Aerated Cavity Length

\begin{tabular}{ccccc}
\hline \multirow{2}{*}{ aerator } & \multicolumn{3}{c}{ Aerated cavity length } & Protective \\
\cline { 2 - 4 } & $\begin{array}{r}\text { Simulated } \\
\text { data }(\mathrm{m} / \mathrm{s})\end{array}$ & $\begin{array}{c}\text { Experimental } \\
\text { data }(\mathrm{m} / \mathrm{s})\end{array}$ & Error (\%) & 110 \\
\hline $1 \#$ & 21.8 & 23.6 & -7.6 & 150 \\
$3 \#$ & 24.1 & 23.2 & 3.9 & 120 \\
\hline
\end{tabular}




\section{Conclusions}

The combination of the Realizable k- $\varepsilon$ model and VOF method was applied to sucessfully simulate the hydraulic characteristics of aerated flow of the free-flow tunnel in Baihetan Hydropower Station.we can get to some conclusions as follows:

(1) The numerical simulation results were in good agreement with the physical model test results. The application of Realizable model and VOF method can simulate aerated flow with free surface efficiently.

(2) The high velocity zone in cross section was symmetrically distributed on both sides after the aerator, the reason for this phenomenon is the air entrainment was mainly mixed by the bottom of two sides wall.

(3) The stable aerated cavity and reasonable length means the aerator design is reasonable in the free-flow tunnel of Baihetan Hydropower Station.

\section{References}

[1]CHEN Wen-xue, XIE Sheng-zong, LIU Zhi-ping, et al. Study on the sidewall aerators of high head ogee spillways, Water Power, 31 (2005) 31-34.

[2]LIU Chao, ZHANG Guang-ke, ZHANG Guang-bi, et al. The optimum shape of aerator at the spillway tunnel of slight slope and low Fr, Journal of Sichuan University(Engineering Science Edition), 39 (2007) 30-35.

[3]WANG Hai-yun, DAI Guang-qing, YANG Yong-quan, et al. Characteristic study on preventing cavitation damage of hydraulic structures side-walls with high head, Journal of Sichuan University(Engineering Science Edition), 38 (2006) 38-43.

[4]LI Ling, CHEN Yong-can, LI Xu-dong. Numerical study on configuration of flood discharge tunnel for cavitation mitigation, Journal of Hydraulic Engineering, (2003) 12-15.

[5]ZHANG Hong-wei, ZHANG Dong, WU Yi-hong, et al. Numerical study on the hydraulic characteristics of water flow in the anti-arc of spillway tunnel, Chinese Journal of Hydrodynamics, 23 (2008) 261-268.

[6]YANG Zhong-chao, DIAO Ming-jun, DENG Jun. Numerical simulation study on hydraulic characteristics of high head large discharge spillway tunnel, Water Resources and Power, 28 (2010) $78-81$.

[7]HUANG Hao, ZHANG Chang-bing, XING Zhi. Three dimensional numerical simulation of hydraulic characteristics and air entrainment to alleviate cavitations of No.1 spillway tunnel of Ertan hydropower station, Journal of Water Resources and Water Engineering, 22 (2011) 168-170.

[8]LUO Yong-qin, DIAO Ming-jun, HE Da ming, et al. Numerical simulation of aeration and cavitation in high dam spillway tunnels, Advances in Water Science, 23 (2012) 110-116.

[9]DENG Jun, XU Wei-lin, LEI Jun, et al. Numerical simulation of hydraulic characteristics of high head spillway tunnel, Journal of Hydraulic Engineering, 36 (2005) 1209-1212.

[10]WANG Fu-jun: Computational fluid dynamics analysis (2004). 